\title{
Electrical Properties and Functional Expression of Ionic Channels in Cochlear Inner Hair Cells of Mice Lacking the $\alpha 10$ Nicotinic Cholinergic Receptor Subunit
}

\author{
María Eugenia Gómez-Casati ${ }^{1}$, Carolina Wedemeyer ${ }^{1}$, Julián Taranda ${ }^{1}$, Marcela Lipovsek ${ }^{1}$, Viviana \\ Dalamon $^{1}$, Ana Belén Elgoyhen ${ }^{1,2}$, ANd Eleonora Katz ${ }^{1,3}$ \\ ${ }^{1}$ Instituto de Investigaciones en Ingeniería Genética y Biología Molecular, Consejo Nacional de Investigaciones Científicas y Técnicas, \\ Vuelta de Obligado 2490, 1428, Buenos Aires, Argentina \\ ${ }^{2}$ Departamento de Farmacología, Facultad de Medicina, Universidad de Buenos Aires, Buenos Aires, Argentina \\ ${ }^{3}$ Departamento de Fisiología, Biología Molecular y Celular, Facultad de Ciencias Exactas y Naturales, Universidad de Buenos \\ Aires, Buenos Aires, Argentina
}

Received: 24 October 2008; Accepted: 11 February 2009; Online publication: 28 February 2009

\begin{abstract}
Cochlear inner hair cells (IHCs) release neurotransmitter onto afferent auditory nerve fibers in response to sound stimulation. During early development, synaptic transmission is triggered by spontaneous $\mathrm{Ca}^{2+}$ spikes which are modulated by an efferent cholinergic innervation to IHCs. This synapse is inhibitory and mediated by the $\alpha 9 \alpha 10$ nicotinic cholinergic receptor (nAChR). After the onset of hearing, large-conductance $\mathrm{Ca}^{2+}$-activated $\mathrm{K}^{+}$channels are acquired and both the spiking activity and the efferent innervation disappear from IHCs. In this work, we studied the developmental changes in the membrane properties of cochlear IHCs from $\alpha 10$ nAChR gene (Chrna10) "knockout" mice. Electrophysiological properties of IHCs were studied by whole-cell recordings in acutely excised apical turns of the organ of Corti from developing mice. Neither the spiking activity nor the developmental functional expression of voltage-gated and/or calcium-sensitive $\mathrm{K}^{+}$channels is altered in the absence of the $\alpha 10$ nAChR subunit. The present results show that the $\alpha 10$ nAChR subunit is not essential for the correct

María Eugenia Gómez-Casati and Carolina Wedemeyer equally contributed to this work.

Correspondence to: Eleonora Katz - Instituto de Investigaciones en Ingeniería Genética y Biología Molecular - Consejo Nacional de Investigaciones Científicas y Técnicas - Vuelta de Obligado 2490, 1428, Buenos Aires, Argentina. Telephone: $+54-11-47832871$; fax: +54 11-47868571; email: ekatz@dna.uba.ar
\end{abstract}

establishment of the intrinsic electrical properties of IHCs during development.

Keywords: calcium spikes, voltage-gated $\mathrm{K}^{+}$ channels, calcium-sensitive $\mathrm{K}^{+}$channels, cholinergic, development, auditory

\section{INTRODUCTION}

Inner hair cells (IHCs) are mechanosensory cells that encode incoming acoustic stimuli in the mammalian cochlea. In rodents, hearing function begins in the second postnatal (P) week. Embryonic and neonatal IHC have functional transduction channels (Kros et al. 1992; Eatock 2003; Housley et al. 2006), voltagegated $\mathrm{K}^{+}$channels (Kros et al. 1998; Marcotti et al. 2003a), calcium-activated SK2 potassium channels (Glowatzki and Fuchs 2000; Katz et al. 2004; Marcotti et al. 2004; Goutman et al. 2005), and also voltagegated $\mathrm{Na}^{+}$(Kros et al. 1992; Marcotti et al. 2003b) and $\mathrm{Ca}^{2+}$ channels (Platzer et al. 2000; Marcotti et al. 2003b; Raffaelli et al. 2004; Johnson and Marcotti 2008). Together, these ion channels underlie, shape, and sustain $\mathrm{Ca}^{2+}$ spiking activity (Kros et al. 1998; Marcotti et al. 2003b, 2004; Housley et al. 2006). This spiking activity drives synaptic transmission before the onset of hearing (Beutner and Moser 2001; Johnson et al. 2007) and may trigger rhythmic or bursting activity of neurons at higher levels of the auditory pathway (Gummer and Mark 1994; Kotak and Sanes 
1995; Eatock 2003). After the onset of hearing (postnatal days 12-13 in mice), spiking completely disappears, mainly due to the expression of a fast $\mathrm{K}^{+}$ current carried by calcium-activated BK channels (Kros and Crawford 1990; Marcotti et al. 2003a).

Before the onset of hearing, olivocochlear fibers transiently innervate IHCs (Simmons et al. 1996; Pujol et al. 1998). The function of this innervation is still unresolved, but it may play a role in the rhythmic firing of immature auditory afferents (Puel 1995; Walsh et al. 1998; Glowatzki and Fuchs 2000; Goutman et al. 2005). Clearly, they can suppress the excitability of IHCs and presumably prevent transmitter release from ribbon synapses known to be functional at this stage (Glowatzki and Fuchs 2000; Glowatzki and Fuchs 2002; Goutman et al. 2005).

This synapse is inhibitory and is mediated by the $\alpha 9 \alpha 10$ nicotinic acetylcholine (ACh) receptor (nAChR; Elgoyhen et al. 1994, 2001; Vetter et al. 1999, 2007; Glowatzki and Fuchs 2000; Weisstaub et al. 2002; Gomez-Casati et al. 2005). Activation of the $\alpha 9 \alpha 10$ nAChR leads to an increase in intracellular $\mathrm{Ca}^{2+}$ and the subsequent opening of SK2 channels (Fuchs and Murrow 1992; Blanchet et al. 1996; Dulon et al. 1998; Oliver et al. 2000; Katz et al. 2004; Marcotti et al. 2004; Nemzou et al. 2006) that hyperpolarize the cells. IHCs express messenger RNA (mRNA) for both $\alpha 9$ and $\alpha 10$ nAChRs subunits beginning in late embryogenesis. The expression of Chrna10, but not that of Chrna9 (Elgoyhen et al. 1994, 2001; Simmons 2002), as well as that of SK2 channels (Katz et al. 2004), drop to undetectable levels in IHCs after the second postnatal week ( P13-14). At the same time, both cholinergic sensitivity (Katz et al. 2004) and efferent innervation disappear from these cells (Liberman et al. 1990; Simmons 2002).

The genetic ablation of the SK2 channel has a dramatic effect on the efferent innervation and in the cholinergic sensitivity of cochlear hair cells (Kong et al. 2008; Murthy et al. 2009). In addition, IHCs from SK2 knockout mice are unable to sustain calcium spiking activity (Marcotti et al. 2004; Johnson et al. 2007). These mutants, however, do not present modifications in the developmental expression of other potassium currents (Johnson et al. 2007; Kong et al. 2008). Considering the dramatic effects that SK2 knockout mice have on the olivocochlear system and on previous work showing a tight dynamic regulation of Chrnalo gene expression in IHCs during synaptogenesis (Elgoyhen et al. 2001; Simmons 2002; Katz et al. 2004), we hypothesized that hair cell physiology might be affected by the lack of expression of the Chrna10 gene. We found, however, that neither the spiking activity nor the developmental functional expression of voltage-gated and calcium sensitive $\mathrm{K}^{+}$ channels are altered by the absence of the $\alpha 10$ nAChR subunit.

\section{METHODS}

Animal procedures and isolation of the organ of Corti

B6Cast mice (N8-N10; Chrna10 ${ }^{+/+}, \mathrm{Chrna10}^{+/}$, and $\mathrm{Chrna10}^{-/-}$), at seven to 17 postnatal days (P7-17; day of birth was considered $\mathrm{P} 0$ ), were anesthetized using pentobarbital and decapitated. All experimental protocols were carried out in accordance with the National Institute of Health guide for the care and use of Laboratory animals (NIH Publications no. 8023) revised 1978. The organ of Corti was exposed and the apical turns were removed for recording as previously described (Glowatzki and Fuchs 2000; Katz et al. 2004; Gomez-Casati et al. 2005) and used within $3 \mathrm{~h}$. Cochlear preparations were mounted under a Leica DMLFS microscope (Leica, D-35578 Wetzlar, Germany) and viewed with differential interference contrast using a 40x water immersion objective and a camera with contrast enhancement (Hamamatsu C2741, Hamamatsu City, Japan).

\section{Electrophysiological recordings}

Methods to record from IHCs were essentially as described (Glowatzki and Fuchs 2000; Katz et al. 2004; Gomez-Casati et al. 2005). Briefly, IHCs were first identified visually and then by their whole-cell capacitance ( 7 to $12 \mathrm{pF}$ ) and their characteristic voltagedependent $\mathrm{Na}^{+}$and $\mathrm{K}^{+}$currents, including at older ages a fast-activating $\mathrm{K}^{+}$conductance (Kros et al. 1998; Marcotti et al. 2003a). Some cells were removed to access IHCs, but mostly, the pipette electrodes were advanced through the tissue under positive pipette pressure.

Currents in IHCs were recorded in the whole-cell patch-clamp configuration using an Axopatch 200B amplifier (Molecular Devices, Sunny Vale, CA 94089, USA), low-pass-filtered at $2-10 \mathrm{kHz}$, and digitized at 5-20 kHz with a Digidata 1200 board (Molecular Devices). Recordings were made at room temperature $\left(22-25^{\circ} \mathrm{C}\right)$. Patch pipettes were pulled from Corning 7056 glass capillaries (Warner Inst. Inc., Hamden, CT 06514, USA), and electrode resistances in the extracellular solution were 5-7 M $\Omega$. In order to reduce the electrode capacitance, the shank of the electrode was coated with sylgard. Working solutions were applied by a gravity-fed multi-channel glass pipette $(\sim 150-\mu \mathrm{M}$ tip diameter $)$ positioned about $300 \mu \mathrm{m}$ from the recorded IHC. In voltage clamp recordings, series resistance $\left(R_{\mathrm{s}} \leq 10-12 \mathrm{M} \Omega\right)$ was compensated on line $0-60 \%$ (most cells only up to $40 \%$ ). Currents 
were not corrected for the residual $R_{\mathrm{s}}$. Therefore, time constants of activation could be somewhat underestimated. In addition, due to IR drop caused by the flow of currents across the uncompensated $R_{\mathrm{s}}$, we would also be making an error in the voltage at which we are measuring the currents and therefore underestimating them, particularly in the case of large currents. Linear leak currents were subtracted offline: leak conductance was calculated between -84 and $-94 \mathrm{mV}$. The indicated holding potentials were corrected off-line for the liquid junction potential $(-4 \mathrm{mV})$ using the PClamp9 specific software.

\section{Solutions}

The extracellular solution was as follows (in $\mathrm{mM}$ ): 155 $\mathrm{NaCl}, 5.8 \mathrm{KCl}, 1.3 \mathrm{CaCl}_{2}, 0.9 \mathrm{MgCl}_{2}, 0.7 \mathrm{NaH}_{2} \mathrm{PO}_{4}, 5.6$ D-glucose, and 10 HEPES buffer; $\mathrm{pH}$ was adjusted to 7.4 with $\mathrm{NaOH}$ (the osmolarity was about 300 $310 \mathrm{mOsm} / \mathrm{kg}$ ). The pipette solutions contained (in $\mathrm{mM}): 150 \mathrm{KCl}, 3.5 \mathrm{MgCl}_{2}, 0.1 \mathrm{CaCl}_{2}, 5$ or 1 ethyleneglycol-bis ( $\beta$-aminoethyl ether)- $N, N, N^{\prime}, N^{\prime}$-tetraacetic acid (EGTA), 5 Hepes buffer, $2.5 \mathrm{Na}_{2} \mathrm{ATP}$; $\mathrm{pH}$ was adjusted to 7.2 with $\mathrm{KOH}$. The osmolarity of intracellular solutions ranged between 270 and $290 \mathrm{mOsm} / \mathrm{kg}$. SK2-sensitive currents in IHCs were recorded using an intracellular solution containing $1 \mathrm{mM}$ EGTA. Action potentials were recorded immediately after rupturing into the cell.

\section{DATA ANALYSIS}

Statistical analyses were carried by analysis of variance (ANOVA) followed by a Tukey's test for multiple comparisons. A value of $p<0.05$ was selected as the criterion for statistical significance. Mean values are quoted as means \pm SEM.

\section{MATERIALS}

ACh chloride, apamin, $\mathrm{Na}_{2} \mathrm{ATP}$, and all other reagents were from Sigma Chemical Co. (St. Louis, MO, USA). EGTA and $\mathrm{Na}_{2}$ ATP were dissolved at the moment of preparing the intracellular solutions. The other drugs were dissolved in distilled water as $1-10$ or $100 \mathrm{mM}$ stocks and stored in aliquots at $-20^{\circ} \mathrm{C}$.

\section{RESULTS}

\section{Spiking activity in IHCs of Chrna10 ${ }^{-1-}$ mice}

Early postnatal IHCs can generate slowly repetitive calcium action potentials spontaneously or during injection of small depolarizing currents (Kros et al.
1998; Glowatzki and Fuchs 2000; Marcotti et al. 2003b). This firing activity is blocked by ACh acting on $\alpha 9 \alpha 10$ nAChR (Glowatzki and Fuchs 2000; Goutman et al. 2005). To evaluate whether the lack of expression of a functional $\alpha 9 \alpha 10 \mathrm{nAChR}$ in IHCs could alter spiking, we examined if IHCs from $\mathrm{Chrna10}^{-/-}$mice were able to generate calcium action potentials before the onset of hearing. As previously reported (Marcotti et al. 2004), at P7-9, spontaneous firing was found very infrequently (only in one cell out of six in Chrna $10^{+/+}$ and never in Chrna10 ${ }^{+/}$and Chrna10 ${ }^{-/}$mice (eight and 14 cells tested, respectively). Therefore, in order to evaluate whether the lack of the $\alpha 10$ subunit affected spiking, we examined action potential features such as threshold, amplitude, duration, and frequency by injecting small depolarizing currents to P7-9 IHCs from Chrna10 ${ }^{+/+}$and Chrna10 ${ }^{-1}$ mice in the whole-cell current clamp configuration. Figure 1A illustrates slowly repetitive calcium action potentials elicited by a constant injected current of 50 and $70 \mathrm{pA}$ in $\mathrm{ChrnalO}^{+/+}$and Chrna10 ${ }^{-1-}$ mice ( $n=5$ and 10 IHCs, respectively) before the onset of hearing. There were no consistent differences in the frequency of action potentials between genotypes (Table 1). Moreover, the amplitude, half-width, and threshold of calcium spikes did not differ between IHCs from $\mathrm{Chrna10}^{+/+}$ and Chrna10 ${ }^{-1-}$ P7-9 mice (Table 1). As can be observed in Figure 1B, superimposed averaged traces of calcium spikes evoked by $70 \mathrm{pA}$ in IHCs from Chrna10 ${ }^{+/+}$and Chrna10 ${ }^{-/}$mice had an identical temporal course (Fig. 1B). This suggested that the $\mathrm{Ca}^{2+}, \mathrm{Na}^{+}$, and $\mathrm{K}^{+}$currents involved in generating and shaping these action potentials (Marcotti et al. 2003b, 2004; Housley et al. 2006) might not be affected by the genetic ablation of the $\alpha 10$ subunit. In addition, no differences between genotypes were found in cell capacitance and resting membrane potential either before or after the onset of hearing (Table 2).

It has been shown that efferent activity can delay or prevent calcium action potentials in neonatal rat IHCs (Glowatzki and Fuchs 2000; Goutman et al. 2005). We thus examined the effect of exogenously applied ACh on the spiking activity of these cells. Consistent with the notion that in IHCs no functional nAChR channels are formed in the absence of the $\alpha 10$ subunit and due to which cholinergic sensitivity is lost (Vetter et al. 2007), $1 \mathrm{mM}$ ACh was not able to abolish the generation of calcium action potentials in IHCs from $\mathrm{ChrnalO}^{-1}$ mice (Fig. 1D, $n=5$ IHCs). Contrastingly, action potential activity was blocked in all IHCs tested from Chrna10 $^{+/+}$mice (Fig. 1D, $n=5$ IHCs). In addition, calcium action potentials were also blocked in 
$A$
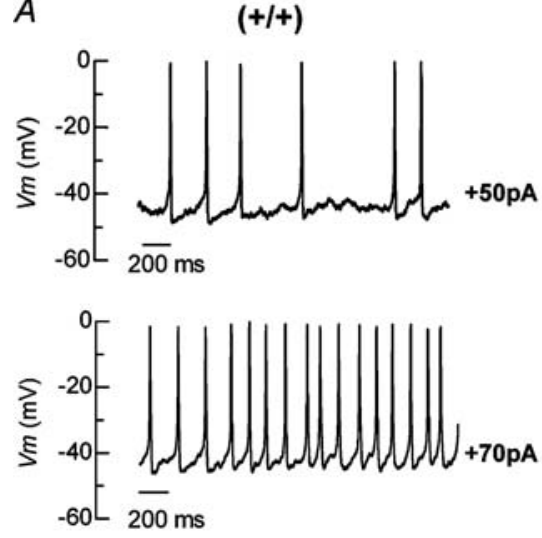

B
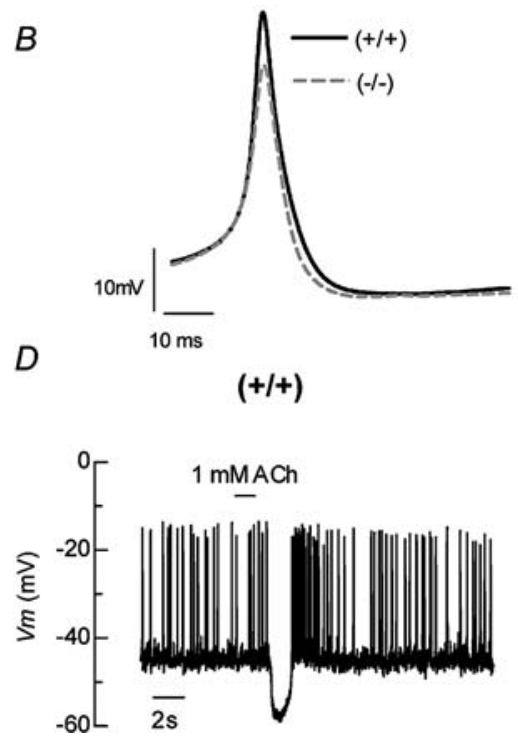

FIG. 1. IHC voltage responses before the onset of hearing. A Representative voltage responses under current clamp from apical coil IHCs before the onset of hearing in $\mathrm{Chrna1O}^{+/+}$and $\mathrm{Chrna10}^{-/}$ mice. To elicit frequent firing of calcium action potentials, we constantly injected a depolarizing current (see protocol in C) into Chrna10 $0^{+/+}$and Chrna10 $0^{-/}$IHCs ( $n=5$ and 10 cells, respectively). B Superimposed average of evoked ( $+70 \mathrm{pA}$ ) calcium action potentials from wild-type (black; 524 events, five cells) and $\alpha 10$ knockout (gray; 877 events, ten cells) mice showing that there are no differences in

\section{TABLE 1}

\begin{tabular}{lrrr}
\hline \multicolumn{4}{c}{ Action potential parameters } \\
\hline \multicolumn{4}{c}{ Chrna10 } \\
\cline { 2 - 4 } & $(+/+)(n=5)$ & $(-/-)(n=10)$ & $p$ value \\
\hline Amplitude $(\mathrm{mV})$ & $33.6 \pm 4.7$ & $27.1 \pm 2.0$ & 0.17 \\
Half-width $(\mathrm{ms})$ & $6.3 \pm 1.0$ & $7.0 \pm 0.7$ & 0.59 \\
Frequency $(\mathrm{Hz})$ & $4.2 \pm 0.4$ & $3.9 \pm 0.8$ & 0.76 \\
Threshold $(\mathrm{mV})$ & $-40.4 \pm 1.4$ & $-36.6 \pm 1.1$ & 0.08 \\
\hline
\end{tabular}

Action potentials for this analysis were elicited by a $+70 \mathrm{pA}$ current step. Values are the mean \pm SEM; $n$ number of $\mathrm{IHC}$ tested. For amplitude, half-width, and frequency, the number of events analyzed were: $524\left(\mathrm{Chrna}^{+/ /+}\right)$and $877\left(\right.$ Chrna $\left.10^{-1 /}\right)$ from five and ten IHCs, respectively. Threshold for spiking activity was determined by a 25 -ms current ramp from 0 to $90 \mathrm{pA}$
$(-/-)$
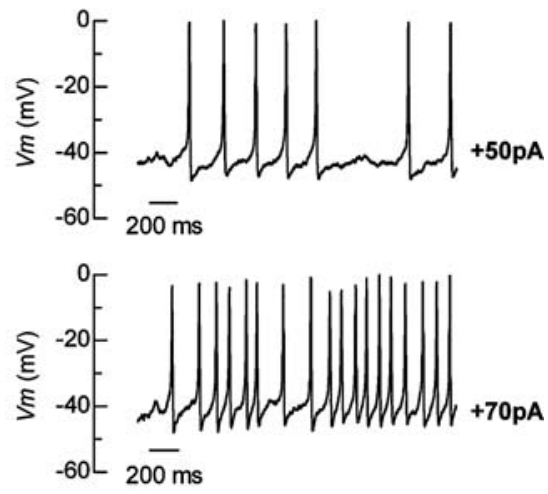

C

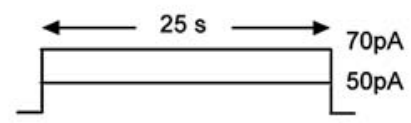

$(-/-)$

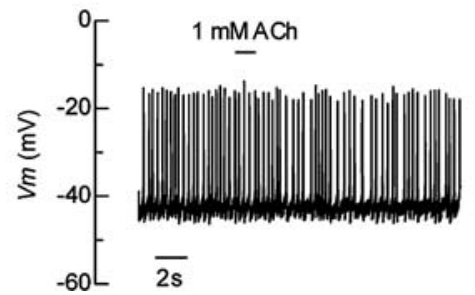

the temporal course of the calcium action potentials between both genotypes (see also Table 1). D Application of $1 \mathrm{mM}$ ACh hyperpolarized the membrane potential from about -47 to $-60 \mathrm{mV}$ and abolished the generation of evoked action potentials in IHCs from both Chrna10 ${ }^{+/+}$( $n=5$ IHCs). In contrast, the application of $1 \mathrm{mM}$ $\mathrm{ACh}$ in IHCs from Chrna10 $0^{-/}$mice did not affect the resting membrane potential and did not abolish the generation of calcium spikes ( $n=5$ IHCs).

three out of three IHCs from Chrna10 $0^{+/}$mice $(n=$ 3, data not illustrated), thus showing that the presence of one allele is sufficient to drive normal olivocochlear efferent function to these cells.

\section{Slowly activating $\mathrm{Ca}^{2+}$-dependent outward currents in IHCs before the onset of hearing}

The inhibitory nature of the olivocochlear synapse in immature IHCs is due to the activation of an SK2 channel after $\mathrm{Ca}^{2+}$ influx through the $\alpha 9 \alpha 10-$ containing nAChRs (Glowatzki and Fuchs 2000; Katz et al. 2004; Marcotti et al. 2004; Gomez-Casati et al. 2005). After the onset of hearing, both 


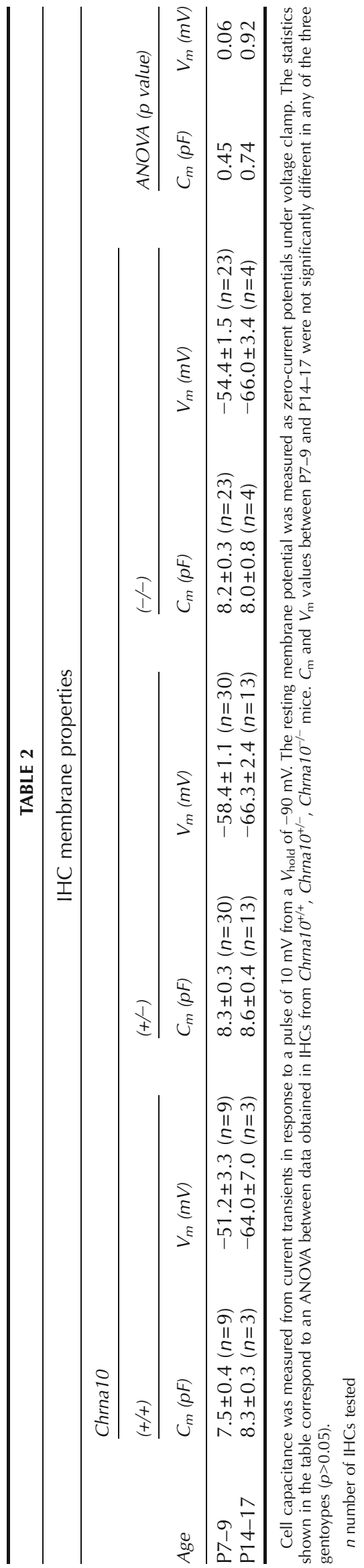

Chrna10 and SK2 gene expression is down-regulated, and this is correlated with the disappearance of ACh-evoked responses (Katz et al. 2004). We therefore evaluated the presence of functional SK2 channels in the Chrna10 ${ }^{-/-}$mice by promoting $\mathrm{Ca}^{2+}$ influx through voltage-dependent $\mathrm{Ca}^{2+}$ channels (Marcotti et al. 2004; Kong et al. 2008). When immature IHCs from Chrna10 ${ }^{+/+}$mice were depolarized for $4 \mathrm{~s}$ from a holding potential of $-84 \mathrm{mV}$ (Fig. 2A) using $1 \mathrm{mM}$ EGTA as the intracellular $\mathrm{Ca}^{2+}$ buffer and $1.3 \mathrm{mM}$ extracellular $\mathrm{Ca}^{2+}$, a slowly activating outward current was evident in $76 \%$ of the wild-type cells tested (Fig. 2B, black traces). Extracellular application of $300 \mathrm{nM}$ apamin, a selective SK2 channel blocker (Kohler et al. 1996), abolished this slowly activating outward $\mathrm{K}^{+}$current (gray traces in Fig. 2B and traces shown in Fig. 2C: here records in the presence of apamin were subtracted from control records, leaving only the apamin-sensitive current), suggesting, as previously demonstrated (Marcotti et al. 2004), that this current was due to the activation of SK2 channels as a result of $\mathrm{Ca}^{2+}$ influx through voltage-gated calcium channels. When a $\mathrm{Ca}^{2+}$-free extracellular solution (containing $1 \mathrm{mM}$ EGTA) was superfused onto immature IHCs, the slowly activating outward current was selectively and reversibly abolished, providing further evidence for its $\mathrm{Ca}^{2+}$ sensitivity (data not shown). The maximum amplitude of the SK2 current measured at steady state $(2 \mathrm{~s})$ at $16 \mathrm{mV}$ in IHCs from Chrna10 ${ }^{-/}$ mice (335.5 $\pm 64.1 \mathrm{pA}, n=6$ cells; Fig. 2E) did not differ from that obtained in IHCs from wild-type mice $(345.2 \pm 73.6 \mathrm{pA}, n=9$ cells; Fig. $2 \mathrm{C} ; p>0.5)$. This current was no longer evident in IHCs of wild type or Chrna10 ${ }^{-1-}$ mice after the onset of hearing (Fig. 2F-I).

\section{Total outward $\mathrm{K}^{+}$currents expressed in IHCs during development}

Depolarizing voltage steps from a holding potential of $-84 \mathrm{mV}$ caused slowly developing voltage-dependent outward $\mathrm{K}^{+}$currents (a delayed rectifier-type $\mathrm{K}^{+}$ current named $I_{\mathrm{K}, \text { neo }}$ for the neonatal cells; Kros et al. 1998; Marcotti et al. 2003a) in all IHCs from the three genotypes before the onset of hearing (Fig. 3B, upper panel). After the onset of hearing, the fast activating $\mathrm{Ca}^{2+}$-dependent $\mathrm{K}^{+}$current $\left(I_{\mathrm{K}, \mathrm{f}}\right)$, characteristic of mature IHCs, was also observed in IHCs from $\mathrm{Chrna1O}^{+/+}$, Chrna10 ${ }^{+/-}$, and Chrna10 ${ }^{-/}$mice (Fig. 3B, lower panel). The size of the outward $\mathrm{K}^{+}$currents increased between $\mathrm{P} 7-9$ and $\mathrm{P} 14-17$ in the three genotypes. Current-voltage curves were generated from the amplitudes of total outward currents measured at two time points: at the beginning (Fig. 3C) and at the end (Fig. 3D) of the 170-ms test pulses illustrated 


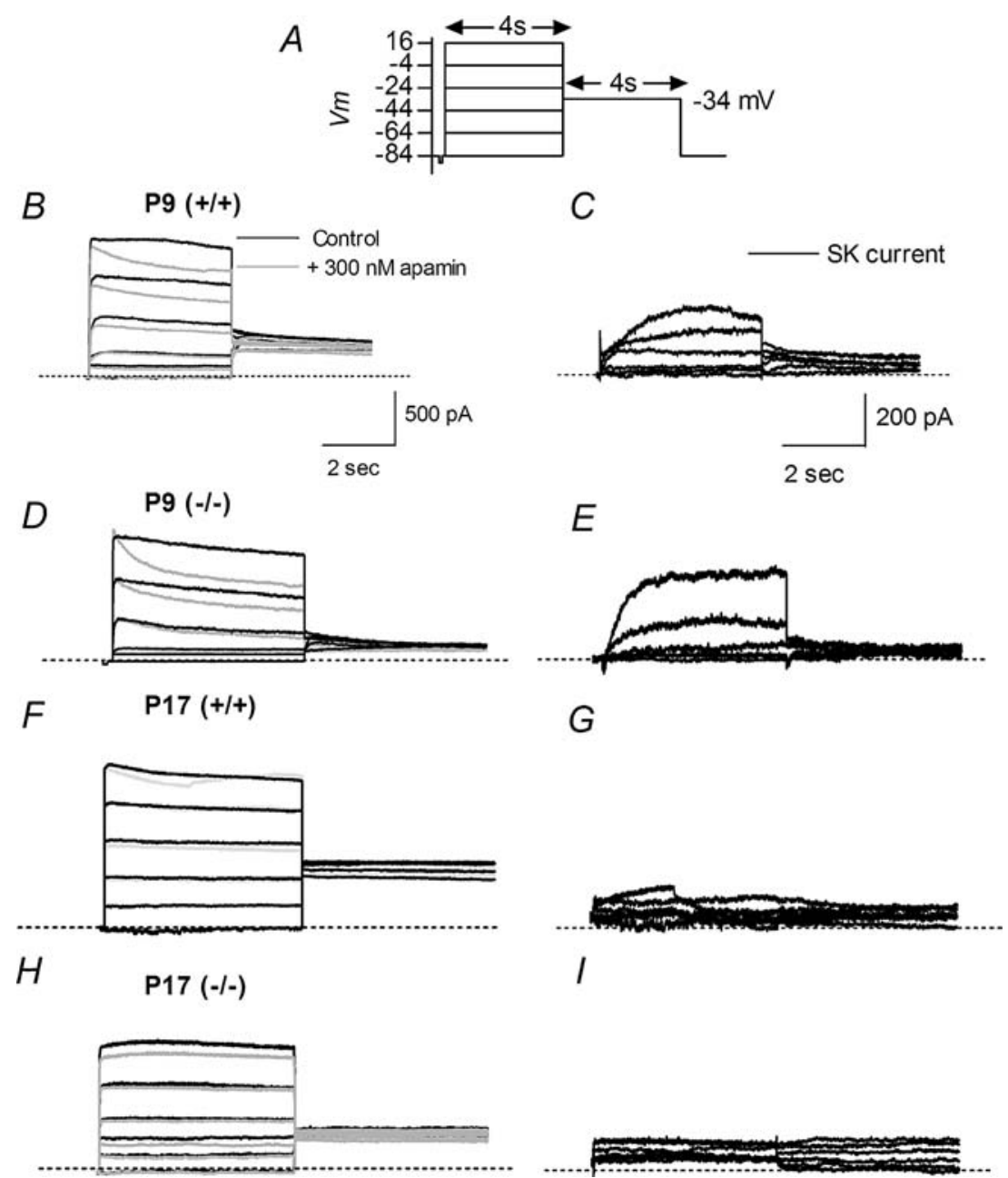

FIG. 2. Development of the slowly activating outward currents in IHCs. A Protocol used to measure the slowly activating outward currents in IHCs. Currents were elicited by 4-s depolarizing voltage steps in 20-mV increments from -84 to $16 \mathrm{mV}$ starting from the holding potential of $-84 \mathrm{mV}$. B Representative outward currents recorded in IHCs from Chrna10 ${ }^{+/+}$mice (P9) in the absence (control) or presence of $300 \mathrm{nM}$ apamin in the extracellular solution. C Subtracting the currents recorded in the presence of apamin from the total currents (control) reveals the presence of SK2 currents $(n=9$ IHCs). D Representative outward currents recorded in IHCs from Chrna10 ${ }^{-/}$mice (P9) in the absence (control) or presence of $300 \mathrm{nM}$

in Figure 3A. As was previously described (Kros et al. 1998; Pyott et al. 2004), the fast component corresponding to $I_{\mathrm{K}, \mathrm{f}}$ was absent at $\mathrm{P} 7-9$ and appeared at P14-17 in IHCs from Chrna10 ${ }^{+/+}$mice (Fig. 3D and Table 3). Similar results were obtained in IHCs from $\mathrm{Chrna10}^{+/-}$and Chrna10 ${ }^{-1-}$ mice. The activation time constant for P7-9 Chrna10 ${ }^{-1-}$ mice was somewhat faster $(\tau=2.4 ; p<0.05)$, however, than that of their wild-type and heterozygous littermates (see Table 3). Notwithstanding, this value is much slower than the one that can be explained by the expression of $I_{\mathrm{K}, \mathrm{f}}$ (Kros et al. 1998). apamin in the extracellular solution. E Subtracting the currents recorded in the presence of apamin from the total currents (control) reveals the presence of SK2 currents $(n=6 \mathrm{IHCs})$. F Representative outward currents recorded from IHCs from P17 wild-type mice in the absence (control) or presence of $300 \mathrm{nM}$ apamin in the extracellular solution. G Subtraction of these currents shows that there are no SK2 currents at this age ( $n=5$ IHCs). $\mathbf{H}$ Representative outward currents recorded from IHCs from Chrna10 ${ }^{-/-}$mice at P17 in the absence (control) or presence of $300 \mathrm{nM}$ apamin in the extracellular solution. I Subtraction of these currents shows that as in $\mathrm{Chrna1O}^{+/+}$mice, there are no SK2 currents at this age in the Chrna10 ${ }^{-1}$ mice ( $\left.n=3 \mathrm{IHCs}\right)$.

In the three genotypes, the amplitude of maximal responses (normalized by whole-cell capacitance to account for any systematic changes in cell size) was smaller in the P7-9 group than in the P14-17 group $(p<0.05$, Fig. 3E). The difference in amplitude between the two age groups was significant for the three genotypes, even though amplitudes at P14-17 could be underestimated by the fact that $R_{\mathrm{s}}$ was only compensated to $40 \%$ (see "Methods"). There were no significant differences, however, in the amplitude of maximal responses in IHCs from Chrna10 ${ }^{+/+}$, $\mathrm{ChrnalO}^{+-}$, and $\mathrm{Chrna10}^{-/-}$in either age group ( $p>$ 
0.05). Outward currents in P14-17 IHCs from the three genotypes had the fast component previously documented as $I_{\mathrm{K}, \mathrm{f}}$ (Kros et al. 1998; Pyott et al. 2004; Table 3). The activation rates of currents recorded from P7-9 preparations at a voltage of $46 \mathrm{mV}$ were slower, consistent with the presence of $I_{\mathrm{K}, \text { neo }}$ (Table 3). Reversal potentials of total outward currents were determined for the three genotypes before and after the onset of hearing and were all close to the $\mathrm{K}^{+}$ equilibrium potential under our experimental conditions $\left(E_{\mathrm{K}}=-82 \mathrm{mV}\right)$, confirming that outward currents were mainly carried by $\mathrm{K}^{+}$ions (Table 3 ).

\section{Steady-state activation of total $\mathrm{K}^{+}$currents during development}

To study whether there were developmental changes in the voltage dependency of activation of total outward $\mathrm{K}^{+}$currents in IHCs of Chrna10 ${ }^{+/+}$, Chrna10 ${ }^{+/}$, and Chrna10 ${ }^{-1}$ mice, tail currents at a fixed membrane potential were analyzed (Fig. 4). From a holding level of $-84 \mathrm{mV}$, the membrane potential was stepped to a test potential of $-44 \mathrm{mV}$ after a series of conditioning depolarizing pulses (170 $\mathrm{ms}$ in duration) in $10-\mathrm{mV}$ steps (see protocol in Fig. 3A). The activation curves were obtained by plotting the normalized instantaneous tail currents (measured $0.2-0.4 \mathrm{~ms}$ after stepping to the test potential) against the different pre-pulse potentials. Data were fitted by a single first-order Boltzmann equation: $I=I_{\max } / 1+\left(\exp \left(\left(V_{50}-V\right) / S\right)\right)$. Tail current amplitude is represented by $I, I_{\max }$ is the maximal tail current amplitude, $V_{50}$ is the potential of half-maximal activation, $V$ is the membrane potential of the preceding voltage step, and $S$ describes the voltage sensitivity of activation. Both $V_{50}$ and the slope factor $(S)$ showed no clear trend with age and no differences across genotypes (Fig. 4B, C).

\section{Inward rectifier $\mathrm{K}^{+}$current}

The inward rectifier $\mathrm{K}^{+}$current $\left(I_{\mathrm{K} 1}\right)$, like Chrna10 and SK2, is transiently expressed in IHCs before the onset of hearing (Marcotti and Kros 1999; Katz et al. 2004). To evaluate if the lack of expression of the $\alpha 10$ subunit alters the expression of this inward rectifier $\mathrm{K}^{+}$ current, we evaluated its onset during development. As illustrated in Figure 5, hyperpolarizing voltage steps between -54 and $-154 \mathrm{mV}$ (in $10-\mathrm{mV}$ decrements), starting from a holding potential of $-64 \mathrm{mV}$ (Fig. 5A), elicited inward currents in P9 IHCs of Chrna10 ${ }^{-/-}$mice and their Chrna10 ${ }^{+/+}$littermates (Fig. 5B). Identical results were found in IHCs from P7-9 Chrna10 ${ }^{+-}$mice (not illustrated). The peak and steady-state $I-V$ curves (Fig. 5C, D, respectively) show that the current became inward negative to $-80 \mathrm{mV}$ in both genotypes, near the $\mathrm{K}^{+}$equilibrium potential.

\section{DISCUSSION}

In this work, we studied the membrane electrical properties of developing cochlear IHCs in $\mathrm{Chrna10}^{-/-}$ mice before and after the onset of hearing. We found that neither the spiking activity in IHCs nor the developmental functional expression of voltage-gated and/or calcium-sensitive $\mathrm{K}^{+}$channels in these cells is altered by the absence of the $\alpha 10 \mathrm{nAChR}$ subunit.

In rodents, cholinergic sensitivity of IHCs is known to peak around postnatal days 7-10 and to disappear after the onset of hearing (Katz et al. 2004). These changes are accompanied by a down-regulation of the expression of two key postsynaptic proteins, the $\alpha 10$ nAChR subunit (Elgoyhen et al. 2001; Simmons 2002; Katz et al. 2004) and the SK2 calcium-sensitive $\mathrm{K}^{+}$ channels (Katz et al. 2004) as well as by the retraction of direct efferent synapses onto IHCs (Liberman et al. 1990; Simmons 2002). The key factors that signal the formation and the dismantling of this transient synapse are still unknown. We have previously shown that the lack of either the $\alpha 9$ or the $\alpha 10 \mathrm{nAChR}$ subunit disrupts the efferent inhibition on the gain of the cochlear amplifier and has a severe impact both on the morphology of the efferent-OHC synapse and in the sensitivity of cochlear hair cells to ACh (Vetter et al. 1999, 2007). Here, we show that the lack of the $\alpha 10$ subunit does not interfere with the normal functional expression and down-regulation of SK2 channels in IHCs (Katz et al. 2004). On the contrary, the genetic deletion of the functionally coupled SK2 channel has an extremely severe impact on the cholinergic efferent innervation (Murthy et al. 2009; Kong et al. 2008) in the cholinergic sensitivity of cochlear hair cells (Kong et al. 2008) and in the normal spiking activity of pre-hearing IHCs (Johnson et al. 2007). SK2 knockout mice lose the olivocochlear fibers and synapses after P18 (Murthy et al. 2009). In addition, both IHCs and OHCs fail to respond to either synaptically released or exogenously applied ACh even though the mRNA levels for both the $\alpha 9$ and the $\alpha 10$ nAChR subunits are similar to those found in wild-type mice (Kong et al. 2008). So it seems that SK2 channels are necessary to trigger the steps leading to the functional localization of the $\alpha 9 \alpha 10$ nAChR at the plasma membrane of IHCs and OHCs. The present results, however, demonstrate that in spite of the concerted regulation of the expression of the Chrna10 and the SK2 genes during development, the $\alpha 10 \mathrm{nAChR}$ subunit is not necessary for the functional expression of the SK2 channel in IHCs.

The present results also show that the lack of the $\alpha 10$ subunit does not cause major alterations either in the functional expression of other voltage-gated and/ or calcium-sensitive $\mathrm{K}^{+}$channels or in the electrical properties of IHCs. Even though spiking activity is 
A

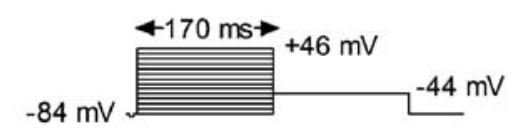

P8

$B$

$(+++)$

$(+/-)$

$(-1-)$
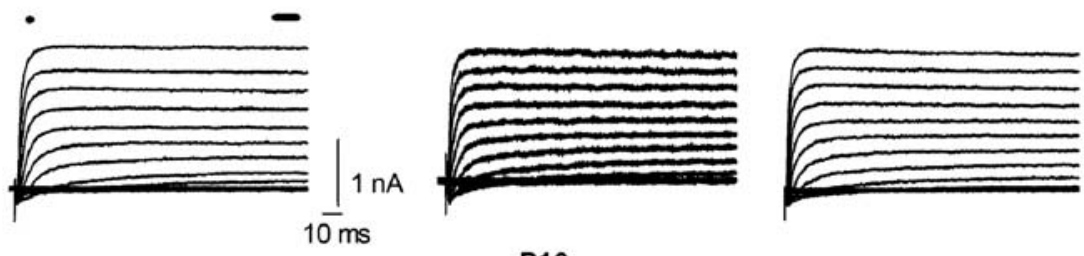

P16

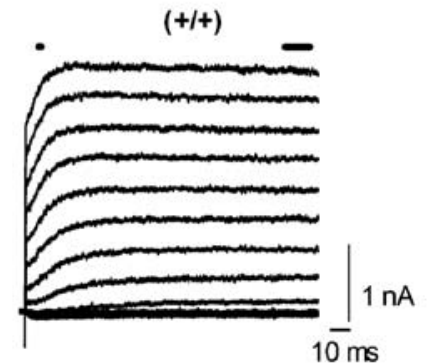

$(+1-)$

$(-/-)$
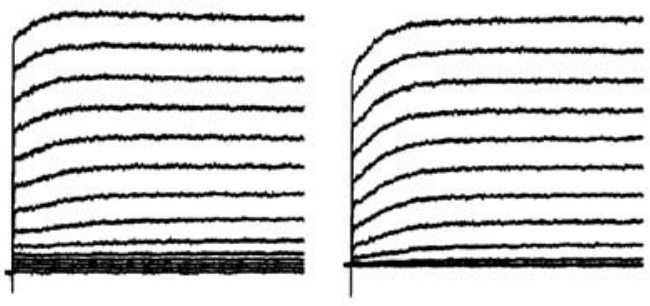

(C)

P7-9 D

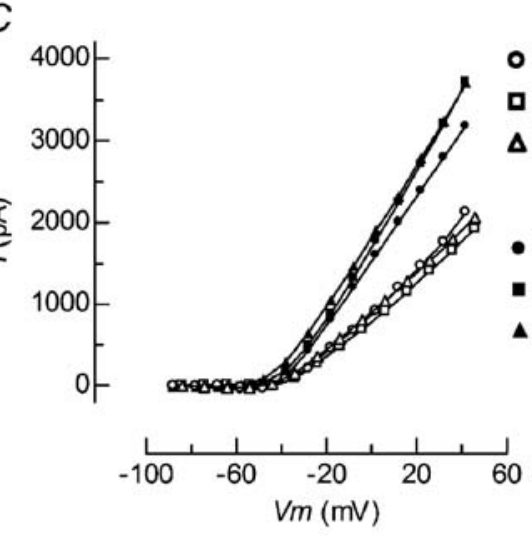

$0(+++)$

a $(+/-)$

$\Delta(-/-)$

P14-17

- $(+/+)$

- $(+/-)$

$\Delta(-/)$

2000
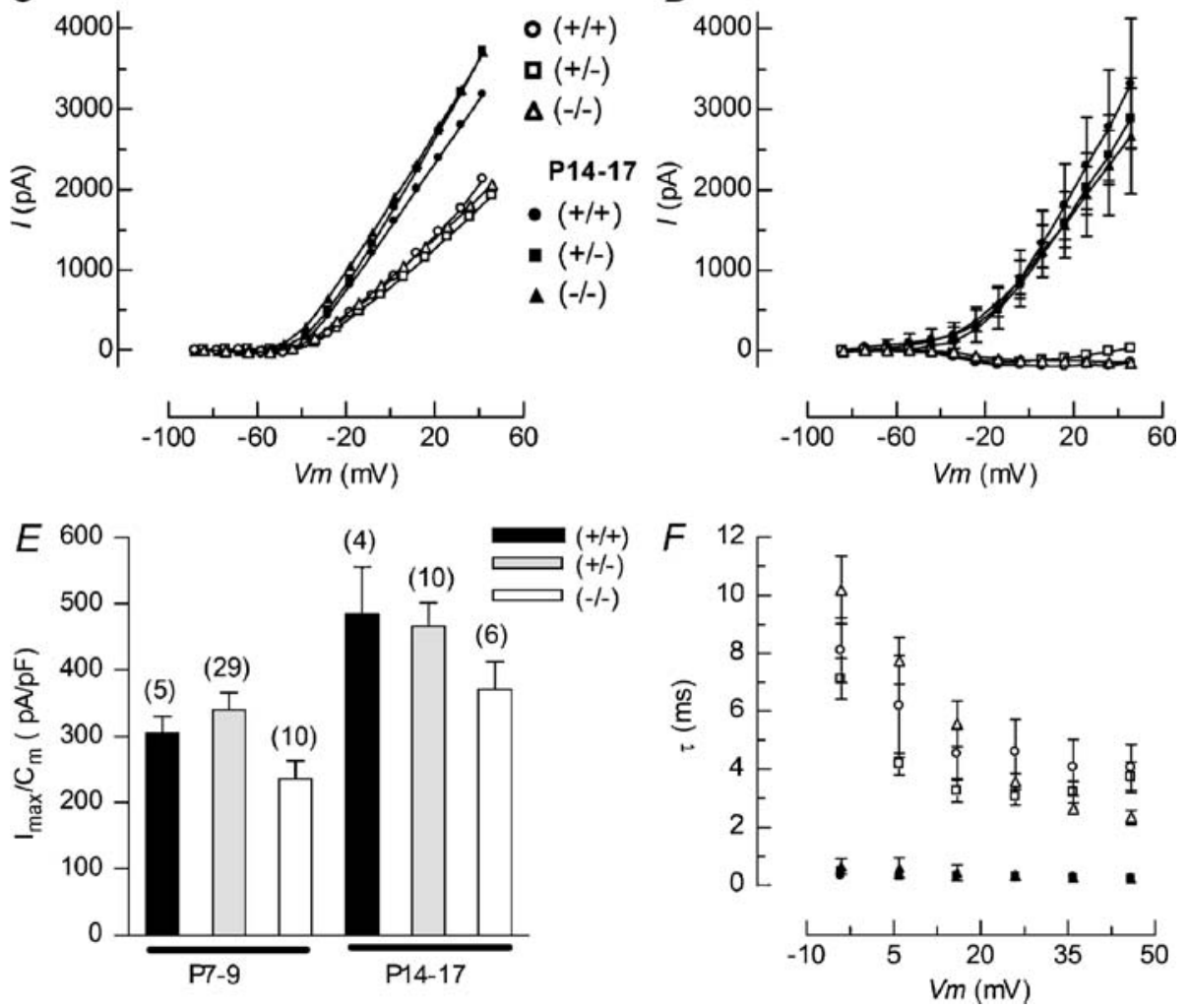

present in the SK2 mutants, this spiking is not sustained (Johnson et al. 2007), as SK2 is necessary for the fast repolarization of the calcium action potentials (Marcotti et al. 2004). Moreover, it was shown that the lack of SK2 channels alters the normal calcium dependence of transmitter release after the onset of hearing (Johnson et al. 2007). The activity of the transient efferent synapse was shown to control 
FIG. 3. Outward $\mathrm{K}^{+}$currents in mouse cochlear IHCs during development. A Pulse protocol used to determine the total outward $\mathrm{K}^{+}$currents. Voltage-dependent currents were obtained by holding the cell at $-84 \mathrm{mV}$ and stepping the voltage to $46 \mathrm{mV}$ in $10-\mathrm{mV}$ increments (170-ms duration). B Representative outward currents in IHCs from Chrna10 ${ }^{+/+}$, Chrna10 $0^{+/}$, and Chrna10 $0^{-/}$mice prior (top records) or after (bottom records) the onset of hearing. Outward currents recorded from IHCs before the onset of hearing (P8) activate slowly in the three genotypes. In contrast, outward currents recorded from IHCs after the onset of hearing (P16) show a rapidly activating component. C Steady-state current-voltage curves of the currents shown in B measured at the long markers (amplitude values obtained between 170 and $182 \mathrm{~ms}$ were averaged) for the three genotypes. D Averaged current-voltage curves of the fast component corresponding to $I_{\mathrm{K}, \mathrm{f}}$ determined at the time of the short markers (only one point was computed) shown in $\mathbf{B}$ for the three genotypes. $\mathbf{E}$ Bar diagram illustrating averaged amplitudes at $46 \mathrm{mV}$ normalized to the mean capacitance $\left(C_{\mathrm{m}}\right)$ in each age group for the three genotypes. For the three genotypes, amplitudes were significantly larger in the P14-17 age group compared to the P7-9 one ( $p$ values were $0.01,0.02$, and 0.03 for $\mathrm{Chrna}^{+/+}, \mathrm{Chrna} 1 \mathrm{O}^{+/}$, and Chrna10 ${ }^{-1}$, respectively). F Time constants of activation $(\tau)$ for these currents are compared over a range of positive command potentials in the three genotypes. Mean \pm SEM in $\mathbf{D}-\mathbf{F}$ were obtained in five, 29, and ten P7-9 IHCs from Chrna10 ${ }^{+/+}$, Chrna10 ${ }^{+/}$, and Chrna10 ${ }^{-/}$, respectively, and in four, ten, and six P14-17 IHCs from Chrna10 ${ }^{+/+}$, Chrna10 $0^{+/}$, and Chrna10 ${ }^{-/}$, respectively.

the firing frequency of calcium action potentials in IHCs (Glowatzki and Fuchs 2000; Goutman et al. 2005). In addition, these $\mathrm{Ca}^{2+}$ spikes trigger transmitter release from the ribbon synapses before the onset of hearing (Beutner and Moser 2001; Johnson et al. 2007). Therefore, even though in the present work we did not test transmitter release from IHCs, we cannot disregard the possibility that the genetic ablation of the $\alpha 10$ nAChR subunit could alter transmitter release from IHC ribbon synapses either before and/or after the onset of hearing.

In agreement with our results, however, the genetic ablation of SK2 channels does not have any major effects on the electrical properties and on the functional expression of $\mathrm{K}^{+}$ion channels during development (Johnson et al. 2007; Kong et al. 2008). These findings with $\alpha 10$ and SK2 knockout mice are surprising, since during development, IHCs undergo major and finely orchestrated changes in the expression of $\mathrm{K}^{+}$(Kros et al. 1998; Marcotti et al. 2003a) and $\mathrm{Ca}^{2+}$ channels (Beutner and Moser 2001), synaptic proteins (Eybalin et al. 2002), spiking activity (Glowatzki and Fuchs 2000; Beutner and Moser 2001; Marcotti et al. 2003a, 2004) and also in their cholinergic sensitivity and pattern of efferent innervation (Liberman et al. 1990; Simmons 2002; Katz et al. 2004). Before the onset of hearing, $\mathrm{Ca}^{2+}$ spikes are driven by the concerted activity of voltage-gated outwardly rectifying $\mathrm{K}^{+}$channels, fast inwardly rectifying $\mathrm{K}^{+}$channels, and voltage-gated $\mathrm{Na}^{+}$ and $\mathrm{Ca}^{2+}$ channels (Eatock and Hurley 2003; Marcotti et al. 2003b; Housley et al. 2006). After the onset of

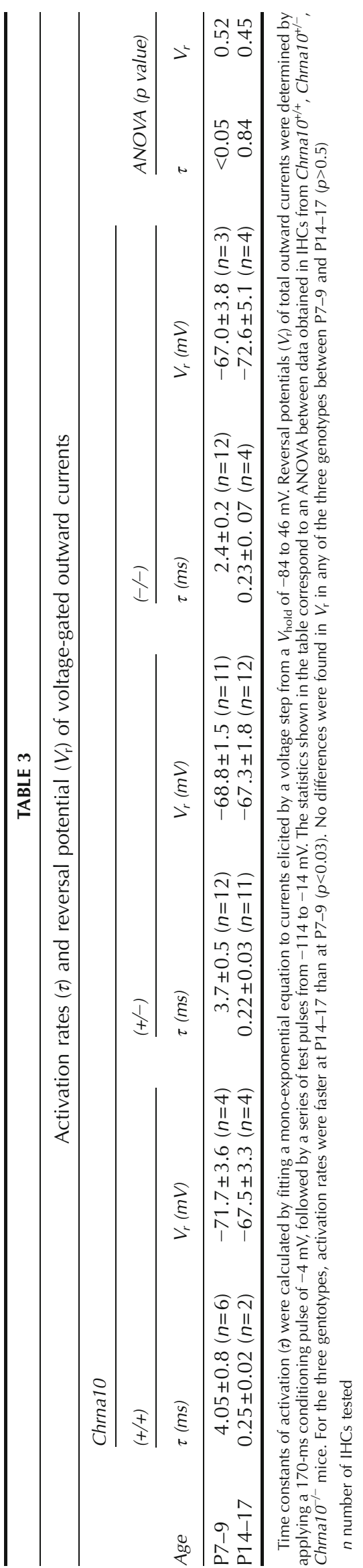



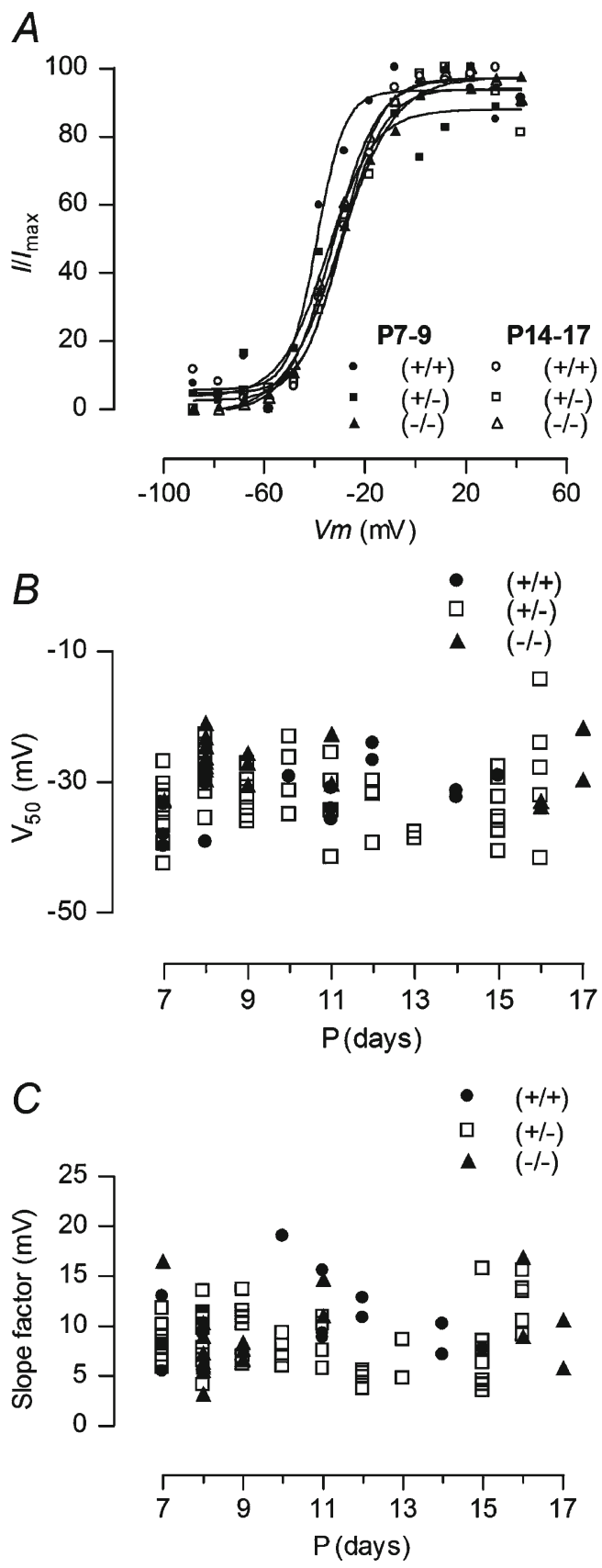

FIG. 4. Activation of outward $\mathrm{K}^{+}$currents during IHC maturation. A Typical examples of normalized steady-state activation curves for total outward currents in IHCs from Chrna10 ${ }^{+/+}$, Chrna10 ${ }^{+/-}$, and Chrna10 ${ }^{-/}$mice prior (P7-9) or after the onset of hearing (P1417). Activation curves were obtained by analyzing tail currents at $-44 \mathrm{mV}$ after a series of conditioning depolarizing steps $(170 \mathrm{~ms}$ in duration) in $10-\mathrm{mV}$ increments from $-84 \mathrm{mV}$ and then plotting the normalized instantaneous tail currents (measured $0.2-0.4 \mathrm{~ms}$ after stepping to the test potential) against the different pre-pulse potentials. Data were fitted by a single first-order Boltzmann equation ( $n=2-12$ IHCs per genotype). B Potential of halfmaximal activation $\left(V_{50}\right)$ for the activation curves of total $\mathrm{K}^{+}$ currents recorded in IHCs from P3 to P17 in the three genotypes. C Slope factor $(S)$ for the activation curves of total $\mathrm{K}^{+}$currents recorded in IHCs from P3 to P17 in the three genotypes $(n=2-12$ IHCs per genotype). hearing, IHC spiking disappears probably because $\mathrm{Na}^{+}$, $\mathrm{Ca}^{2+}$, and fast inwardly rectifying channels become less numerous, whereas outwardly rectifying $\mathrm{K}^{+}$channels increase in number (Eatock and Hurley 2003; Marcotti et al. 2003b). The correct developmental functional maturation of IHCs has been shown to be highly sensitive to alterations in the expression of some of these proteins. For example, mice lacking $\mathrm{Ca}_{\mathrm{v}} 1.3$ channels show not only alterations in afferent synaptic transmission and spiking activity but also in the expression of large-conductance $\mathrm{Ca}^{2+}$-activated $\mathrm{K}^{+}$channels (BK channels; Brandt et al. 2003). In addition, the normal developmental pattern of cholinergic sensitivity, efferent innervation, and SK2 channel expression are altered in $\mathrm{Ca}_{\mathrm{v} 1.3}$ knockout mice. Thus, contrary to the cessation of ACh sensitivity normally seen in wild-type mice at around P13-14 (Katz et al. 2004), it persists up to 6 weeks after birth in $\mathrm{Ca}_{\mathrm{v} 1.3}$ knockout mice (Brandt et al. 2003; Nemzou et al. 2006). Moreover, during this critical developmental window, several studies have shown that modifications in the expression of proteins involved in thyroid hormone signaling alter IHC spiking activity, probably due to the lack of expression of $\mathrm{BK}$ and KCNQ4 channels together with an increase in calcium influx (Eatock et al. 1998; Brandt et al. 2007; Sendin et al. 2007). These data indicate that there is a concerted regulation of the functional expression of ion channels during IHC maturation. Therefore, we expected that the lack of the $\alpha 10 \mathrm{nAChR}$ subunit, and thus the absence of a functional nAChR receptor in IHCs (Vetter et al. 2007), would interfere with the normal pattern of expression of other ion channels. Notwithstanding, this was not the case as shown by the normal development of the electrophysiological properties of developing IHCs from Chrna10 ${ }^{-1}$ mice.

The spiking activity (threshold, generation, and frequency) of neonatal IHCs of Chrna10 ${ }^{-/-}$mice was identical to those of their wild-type and heterozygous littermates. Moreover, the amplitude and temporal course of the $\mathrm{Ca}^{2+}$ spikes were not altered by the lack of the $\alpha 10$ subunit. These results are in line with the lack of significant changes in the functional expression of $\mathrm{K}^{+}$ionic channels found in the present work. They also strongly suggest that the developmental expression of both $\mathrm{Ca}^{2+}$ and $\mathrm{Na}^{+}$ channels is normal in IHCs from $\mathrm{Chrna}^{-/-}$mice (Marcotti et al. 2003a, 2004; Housley et al. 2006). As mentioned above, both the generation and the frequency of this spiking activity in IHCs are regulated by the transient inhibitory efferent cholinergic innervation from the olivocohlear system (Glowatzki and Fuchs 2000; Goutman et al. 2005) that is mediated by the postsynaptic $\alpha 9 \alpha 10 \mathrm{nAChR}$ (Elgoyhen et al. 1994, 2001; Glowatzki and Fuchs 2000; Katz et al. 2004; Marcotti et al. 2004; Gomez-Casati et al. 2005). As expected, due to the lack of cholinergic sensitivity of 


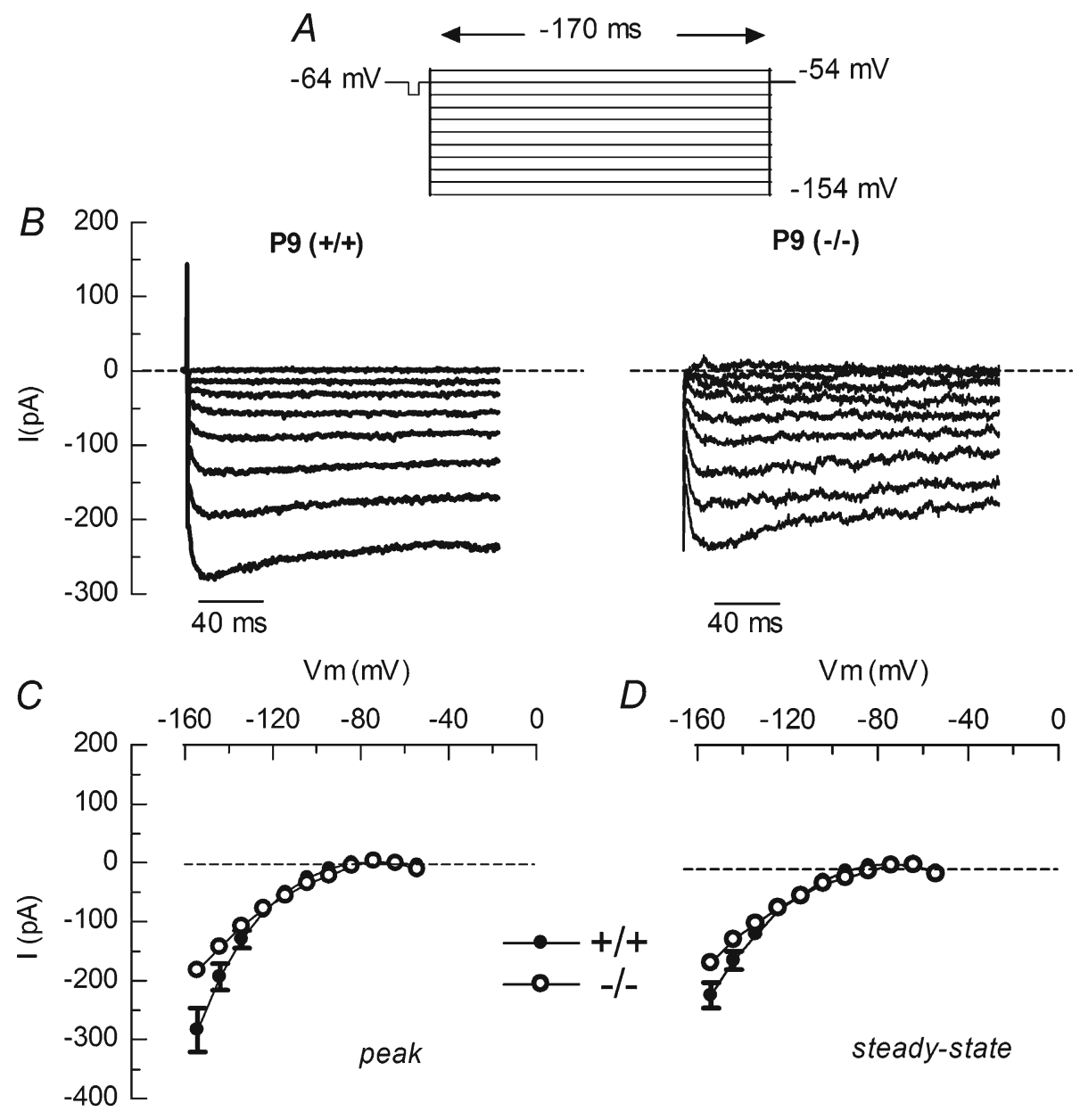

FIG. 5. Inwardly rectifying $\mathrm{K}^{+}$current in cochlear IHCs. A Protocol used to measure inwardly rectifying $\mathrm{K}^{+}$currents in IHCs. These currents were obtained by using $10-\mathrm{mV}$ voltage steps between -24 and $-154 \mathrm{mV}$ starting from a holding potential of $-64 \mathrm{mV}$. B Typical current responses in IHCs from Chrna10 ${ }^{+/+}$and Chrna10 ${ }^{-/-}$P9

IHCs from Chrna10 ${ }^{-/}$mice (Vetter et al. 2007), neither the generation of calcium action potentials nor their frequency was sensitive to ACh.

\section{ACKNOWLEDGMENTS}

This work was supported by grants from Howard Hughes Medical Institute to ABE, Agencia Nacional de Promoción Científica y Técnológica to ABE and EK, University of Buenos Aires to ABE and EK and Consejo Nacional de Investigaciones Científicas y Técnicas to EK.

\section{REFERENCES}

Beutner D, Moser T. The presynaptic function of mouse cochlear inner hair cells during development of hearing. J. Neurosci. 21:4593-4599, 2001.

Blanchet C, Erostegui C, Sugasawa M, Dulon D. Acetylcholineinduced potassium current of guinea pig outer hair cells: its dependence on a calcium influx through nicotinic-like receptors. J. Neurosci. 16:2574-2584, 1996. mice. C Peak current-voltage curves from Chrna10 $0^{+/+}$(filled circles) and Chrna10 ${ }^{-/}$(clear circles; $n=4$ IHCs per genotype). D Steadystate current-voltage curves from Chrna10 $0^{+/+}$(filled circles) and Chrna10 $^{-1-}$ (clear circles; $n=8$ IHCs per genotype).

Brandt A, Striessnig J, Moser T. CaV1.3 channels are essential for development and presynaptic activity of cochlear inner hair cells. J. Neurosci 23:10832-10840, 2003.

Brandt N, Kuhn S, Munkner S, Braig C, Winter H, Blin N, Vonthein R, KNipper M, Engel J. Thyroid hormone deficiency affects postnatal spiking activity and expression of $\mathrm{Ca}^{2+}$ and $\mathrm{K}^{+}$ channels in rodent inner hair cells. J. Neurosci 27:3174-3186, 2007.

Dulon D, Luo L, Zhang C, Ryan AF. Expression of small-conductance calcium-activated potassium channels (SK) in outer hair cells of the rat cochlea. Eur. J. Neurosci 10:907-915, 1998.

ЕАтоск RA. Auditory physiology: listening with $\mathrm{K}^{+}$channels. Curr. Biol 13:R767-R769, 2003.

EATock RA, HuRLEY KM. Functional development of hair cells. Curr. Top. Dev. Biol 57:389-448, 2003.

Eatock RA, Rusch A, Lysakowski A, SAeki M. Hair cells in mammalian utricles. Otolaryngol. Head Neck Surg 119:172-181, 1998.

Elgoyhen AB, Johnson DS, Boulter J, Vetter DE, Heinemann S. Alpha 9: an acetylcholine receptor with novel pharmacological properties expressed in rat cochlear hair cells. Cell 79:705-715, 1994.

Elgoyhen A, Vetter D, Katz E, Rothlin C, Heinemann S, Boulter J. Alpha 10: a determinant of nicotinic cholinergic receptor function in mammalian vestibular and cochlear mechanosensory hair cells. PNAS U. S. A 98:3501-3506, 2001. 
Eybalin M, Renard N, Aure F, Safieddine S. Cysteine-string protein in inner hair cells of the organ of Corti: synaptic expression and upregulation at the onset of hearing. Eur. J. Neurosci 15:14091420, 2002.

Fuchs PA, Murrow BW. Cholinergic inhibition of short (outer) hair cells of the chick's cochlea. J. Neurosci 12:800-809, 1992.

Glowatzki E, Fuchs PA. Cholinergic synaptic inhibition of inner hair cells in the neonatal mammalian cochlea. Science 288:23662368, 2000.

Glowatzki E, Fuchs P. Transmitter release at the hair cell ribbon synapse. Nat. Nerosci 5:147-154, 2002.

Gomez-Casati ME, Fuchs PA, Elgoyhen AB, Katz E. Biophysical and pharmacological characterization of nicotinic cholinergic receptors in rat cochlear inner hair cells. J. Physiol 566:103$118,2005$.

Goutman JD, Fuchs PA, Glowatzki E. Facilitating efferent inhibition of inner hair cells in the cochlea of the neonatal rat. J. Physiol 566:49-59, 2005.

Gummer AW, Mark RF. Patterned neural activity in brain stem auditory areas of a prehearing mammal, the Tammar wallaby (Macropus eugenii). Neuroreport 5:685-688, 1994.

Housley GD, Marcotti W, Navaratnam D, Yamoah EN. Hair cellsbeyond the transducer. J. Membr. Biol 209:89-118, 2006.

Johnson SL, Adelman JP, Marcotti W. Genetic deletion of SK2 channels in mouse inner hair cells prevents the developmental linearization in the $\mathrm{Ca}^{2+}$ dependence of exocytosis. J. Physiol 583:631-646, 2007.

Johnson SL, Marcotti W. Biophysical properties of CaV1.3 calcium channels in gerbil inner hair cells. J. Physiol 586:1029-1042, 2008.

Katz E, Elgoyhen AB, Gomez-Casati ME, Knipper M, Vetter DE, Fuchs PA, GLOWATZKi E. Developmental regulation of nicotinic synapses on cochlear inner hair cells. J. Neurosci 24:7814-7820, 2004.

Kohler M, Hirschberg B, Bond CT, Kinzie JM, Marrion NV, Maylie J, Adelman JP. Small-conductance, calcium-activated potassium channels from mammalian brain. Science 273:1709-1714, 1996.

Kong JH, Adelman JP, Fuchs P. Expression of the SK2 calciumactivated potassium channel is required for cholinergic function in mouse cochlear hair cells. J. Physiol. 586(22):5471-5485, 2008.

KoTAK VC, SANES DH. Synaptically evoked prolonged depolarizations in the developing auditory system. J. Neurophysiol 74:1611$1620,1995$.

Kros CJ, Crawford AC. Potassium currents in inner hair cells isolated from the guinea-pig cochlea. J. Physiol. (Lond) 421:263-291, 1990.

Kros CJ, Rusch A, RichaRdson GP. Mechano-electrical transducer currents in hair cells of the cultured neonatal mouse cochlea. Proc. R. Soc. Lond. B Biol. Sci 249:185-193, 1992.

Kros CJ, Ruppersberg JP, Rusch A. Expression of a potassium current in inner hair cells during development of hearing in mice. Nature 394:281-284, 1998.

Liberman MC, Dodds LW, Pierce S. Afferent and efferent innervation of the cat cochlea: quantitative analysis with light and electron microscopy. J. Comp. Neurol 301:443-460, 1990.

Marcotti W, Kros CJ. Developmental expression of the potassium current $I_{\mathrm{K}, \mathrm{n}}$ contributes to maturation of mouse outer hair cells. J. Physiol 520(Pt 3):653-660, 1999.
Marcotti W, Johnson SL, Holley MC, Kros CJ. Developmental changes in the expression of potassium currents of embryonic, neonatal and mature mouse inner hair cells. J. Physiol 548:383-400, 2003a.

Marcotti W, Johnson SL, Rusch A, Kros CJ. Sodium and calcium currents shape action potentials in immature mouse inner hair cells. J. Physiol 552:743-761, 2003b.

Marcotti W, Johnson SL, Kros CJ. A transiently expressed SK current sustains and modulates action potential activity in immature mouse inner hair cells. J. Physiol 560:691-708, 2004.

Murthy V, Maison SF, Taranda J, Haque N, Bond CT, Elgoyhen AB, Adelman JP, Liberman MC, Vetter DE. SK2 channels are required for function and long-term survival of efferent synapses on mammalian outer hair cells. Mol. Cell Neurosci. 40:39-49, 2009.

Nemzou NR, Bulankina AV, Khimich D, Giese A, Moser T. Synaptic organization in cochlear inner hair cells deficient for the CaV1.3 (alpha1D) subunit of L-type $\mathrm{Ca}^{2+}$ channels. Neuroscience 141:1849-1860, 2006.

Oliver D, Klocker N, Schuck J, Baukrowttz T, Ruppersberg JP, Fakler B. Gating of $\mathrm{Ca}^{2+}$-activated $\mathrm{K}^{+}$channels controls fast inhibitory synaptic transmission at auditory outer hair cells. Neuron 26:595-601, 2000.

Platzer J, Engel J, Schrott-Fischer A, Stephan K, Bova S, Chen H, Zheng H, Striessnig J. Congenital deafness and sinoatrial node dysfunction in mice lacking class D L-type $\mathrm{Ca}^{2+}$ channels. Cell 102:89-97, 2000.

Puel JL. Chemical synaptic transmission in the cochlea. Prog. Neurobiol 47:449-476, 1995.

Pujol R, Lavigne-Rebillard M, Lenoir M. Development of sensory and neural structures in the mammalian cochlea. In: Rubel EW, Popper AN, Fay RR (eds) Development of the Auditory System. New York, Springer, pp. 146-192, 1998.

Pyott SJ, Glowatzki E, Trimmer JS, Aldrich RW. Extrasynaptic localization of inactivating calcium-activated potassium channels in mouse inner hair cells. J. Neurosci 24:9469-9474, 2004.

Raffaelli G, Saviane C, Mohajerani MH, Pedarzani P, Cherubini E. BK potassium channels control transmitter release at CA3-CA3 synapses in the rat hippocampus. J. Physiol 557:147-157, 2004.

Sendin G, Bulankina AV, Riedel D, Moser T. Maturation of ribbon synapses in hair cells is driven by thyroid hormone. J. Neurosci 27:3163-3173, 2007.

Simmons DD. Development of the inner ear efferent system across vertebrate species. J. Neurobiol 53:228-250, 2002.

Simmons DD, Mansdorf NB, KIM JH. Olivocochlear innervation of inner and outer hair cells during postnatal maturation: evidence for a waiting period. J. Comp. Neurol 370:551-562, 1996.

Vetter DE, Liberman MC, Mann J, Barhanin J, Boulter J, Brown MC, Saffiote-Kolman J, Heinemann SF, Elgoyhen AB. Role of alpha9 nicotinic ACh receptor subunits in the development and function of cochlear efferent innervation. Neuron 23:93-103, 1999.

Vetter de, Katz E, Maison SF, Taranda J, Turcan S, Ballestero J, Liberman MC, Elgoyhen AB, Boulter J. The alpha10 nicotinic acetylcholine receptor subunit is required for normal synaptic function and integrity of the olivocochlear system. Proc. Natl. Acad. Sci. U. S. A 104:20594-20599, 2007.

Walsh E, McGee J, McFadden S, Liberman M. Long-term effects of sectioning the olivocochlear bundle in neonatal cats. J. Neurosci 18:3859-3869, 1998.

Weisstaub N, Vetter DE, Elgoyhen AB, Katz E. The alpha9alpha10 nicotinic acetylcholine receptor is permeable to and is modulated by divalent cations. Hear Res 167:122-135, 2002. 